\title{
Teachers-IN-Service Program in Manitoba
}

\author{
Witold Kinsner, Dario Schor, Kathryn Marcynuk, and Troy Denton \\ Department of Electrical and Computer Engineering \\ University of Manitoba, Winnipeg, MB, Canada R3T 5V6 \\ \{kinsner@ece.umanitoba.ca | dario_schor@umanitoba.ca | ummarcyk@cc.umanitoba.ca | \\ umdentot@cc.umanitoba.ca\}
}

\begin{abstract}
This paper describes examples of a new range of activities intended to enhance the exposure of senior high-school students to engineering, technology, applied science and science. The activities are termed Teachers-in-Service Program (TISP), and have been proposed by the Institute of Electrical and Electronics Engineers (IEEE). Shortly after IEEE Canada brought TISP to this country, IEEE Winnipeg Section brought it to Manitoba. Our TISP activities to date have been very extensive and comprehensive [1].

The mission of TISP is to foster interest in engineering, science and mathematics among students from grades 7 through 12 by providing teachers with tools and training (e.g., [2]) that can be used to give students interesting experience with science and engineering topics in the classroom. TISP provides a forum for IEEE volunteers to demonstrate the application of engineering, science and mathematics concepts by sharing their real-world experiences with local preuniversity educators. IEEE offers training workshops for its volunteers on how to provide the in-service program to local teachers. IEEE Canada provided two such TISP workshops, one in 2009, and one in 2011. Since 2001, over 130 in-service presentations have been developed and delivered by IEEE volunteers. Approximately 3,200 pre-university educators have participated in the in-service program, impacting almost 350,000 students worldwide. All 20 IEEE Canada Sections are now active in TISP.
\end{abstract}

In Manitoba, we have expanded the TISP activities to include not only teachers, but also parents and students themselves. Our TISP activities are segmented into three classes: Tier1 that dedicated to students mostly (e.g., focused presentations, demonstrations and tours that reached over 1350 students in the previous year), Tier2 involving teachers mostly (e.g., workshops [3]), and Tier3 engaging students, teachers and parents (e.g., Space Camp [4], Near-Space Experiments, and communications with satellites through the University of Manitoba ground station [5]).

\section{References}

[1] Witold Kinsner, "Creating excitement about learning and teaching," presented at the IEEE Canada 2011 TISP Workshop (Toronto, ON, April 28-29, 2011) 55 pp., 2011.

[2] TryEngineering, 2011. Available as of February 10, 2012 from http://www.tryengineering.org/

[3] Witold Kinsner, M. G. (Ron) Britton, and Jeff Cieszecki, "Teaching-teachers: Could I design, build, and test a tiny smart robot?" in Proc. of the Canadian Engineering Education Conference, CEEC11 (St. John's, NL: June 6-8, 2011), 7 pp., 2011.

[4] Witold Kinsner, M.G.(Ron) Britton, Jeff Cieszecki, Wayne A. Ellis, Alan Thoren, Dario Schor, Brian Statham, Greg Linton, Tom Tessier, Rob Striemer, Colleen Flather, Barbara Bowen, and Norman Lee, "A space adventure camp and pre-university outreach," in Proc. of the Canadian Engineering Education Conference (St. John's, NL; June 6-8, 2011) 8 pp., 2011.

[5] Witold Kinsner, M.D.(Ron) Britton, Dario Schor, Arash Fazel Darbandi, Kris Goodmanson, Cody Friesen, Emily Bashford, "Preliminary experience from the Canadian Satellite Design Challenge," in Proc. of the Canadian Engineering Education Conference (St. John's, NL; June 6-8, 2011) 6 pp., 2011 